\title{
In-utero transmission of SARS CoV-2 infection during delta variant outbreak: first Australian experience
}

\author{
Robert C. Duguid ${ }^{1} \cdot$ Srinivas Bolisetty ${ }^{1}\left[\right.$ - Fatima Anne Perez ${ }^{1} \cdot$ Tim Schindler $^{1} \cdot$ Pamela Palasanthiran $^{2} \cdot$ Zin Naing $^{3}$
}

Received: 5 October 2021 / Accepted: 25 January 2022 / Published online: 8 February 2022

(c) The Author(s) 2022

\section{Dear Editor,}

We read the case report published by Kularni et al. [1] in Infection with great interest and respond to it with a case of our own that provides further evidence of the potential for in-utero transmission of SARS-CoV-2. Our case occurred during the current outbreak of the Delta variant in Sydney, Australia. To our knowledge this report also describes the first case of neonatal COVID in an Australian Tertiary Newborn Care Centre.

The mother is a 25 -year-old woman who has no significant past medical history. The current pregnancy was uncomplicated prior to SARS-CoV-2 infection. Her 29-year-old husband first tested positive for SARS-CoV-2 after developing mild symptoms of COVID-19. Three days later, the mother developed a sore throat and nausea and subsequently tested positive for SARS-CoV-2. Both parents were unvaccinated and had mild COVID-19 illness that did not require hospitalisation. On day 8 of COVID-19 illness, the mother presented to the hospital with abdominal pain, vaginal bleeding and decreased foetal movements. Placental abruption was presumed and due to an abnormal cardiotocography (CTG), the baby was delivered by pre-labour caesarean section at 32 weeks and 6 days gestation with a birthweight of $1933 \mathrm{~g}$ (73rd percentile). The female infant developed respiratory distress soon after birth requiring bubble continuous positive airway pressure (CPAP) therapy followed by intubation, mechanical ventilation and surfactant

Srinivas Bolisetty

srinivas.bolisetty@health.nsw.gov.au

1 Newborn Care Services, Royal Hospital for Women, Sydney, Australia

2 Department of Immunology and Infectious Diseases, Sydney Children's Hospital, Sydney, Australia

3 Serology and Virology Division (SAViD), NSW Health Pathology Randwick, Prince of Wales Hospital, Sydney, NSW 2031, Australia therapy. She was extubated to CPAP at $24 \mathrm{~h}$ of age and subsequently weaned to air on day 5 of life. She continued to have intermittent rhinorrhoea and occasional diarrhea up to day 15 of life. The remainder of the course was consistent with prematurity.

National COVID-19 guidance for neonatal units in Australia recommend neonates of COVID-19 positive mothers are not routinely tested, but if clinically indicated (as in our case), the case is discussed with the local infectious diseases team. This recommendation was made based on concern that day 0 testing may represent maternal contamination and not infection. There is no clear guidance or recommendation for testing of amniotic fluid, placenta or cord blood. The infant was first tested for SARS-CoV-2 RNA by real-time PCR (Seegene Inc., Seoul, Korea) of a nasopharyngeal sample at $60 \mathrm{~h}$ of life and this was positive. The specimen demonstrated a low cycle threshold ( $\mathrm{Ct}=14$ for $\mathrm{E}-, \mathrm{N}-$, and RdRP/ $\mathrm{S}$-gene) indicating a high viral load. SARS-CoV-2 RNA was also detected in faecal and urine samples, with $\mathrm{Ct}$ values ranging from 24 to 34 . Another nasopharyngeal sample collected at 9 days of life had SARS-CoV-2 RNA detected at $\mathrm{Ct}=18$ for ORF1a and E genes (Roche Diagnostics, Indianapolis, USA), indicating the viral load remained high. On day 12 of life Abbott Architect SARS-CoV-2 (anti-spike) IgM EIA (Abbott Laboratories, Chicago, USA) was positive and Euroimmun anti-SARS-CoV-2 (anti-spike) IgG EIA (Euroimmun, LüBeck, Germany) was negative. The infant then tested positive for Abbott Architect SARS-CoV-2 IgG EIA (Abbott Laboratories, Chicago, USA) on day 28 of life, suggestive of either seroconversion or transfer of maternal antibody via breastmilk. The clinical history and investigations are summarised in Fig. 1.

Potential mechanisms of maternal transfer of SARS CoV-2 to the infant include (1) in-utero transmission either transplacentally or via ingestion by the fetus of viral particles in amniotic fluid, (2) intrapartum through direct contamination of infected amniotic fluid or maternal secretions and (3) post-partum through direct contact ${ }^{2}$. Reported rates 


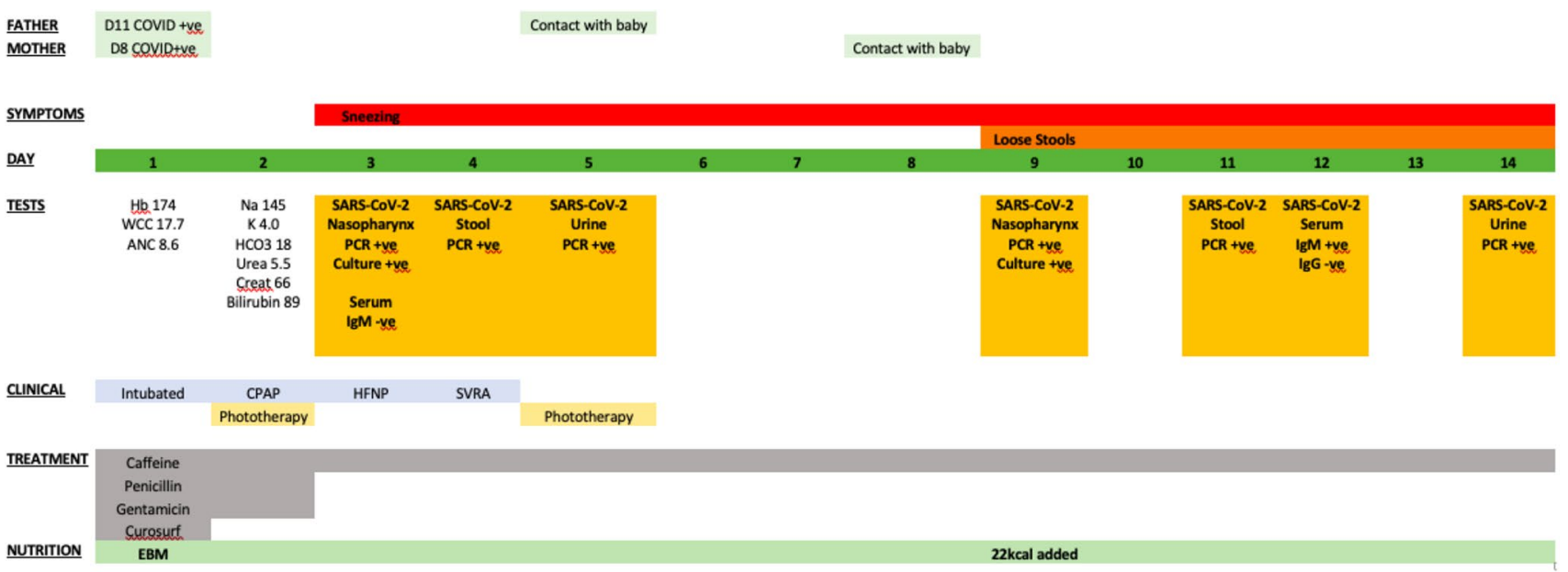

Fig. 1 Timeline of symptoms and laboratory parameters of the SARS-CoV-2 infected newborn. $H b$ haemoglobin $(\mathrm{g} / \mathrm{L}), W C C$ white blood cell count $\left(\times 10^{\wedge} 9 / \mathrm{L}\right), \quad A N C$ absolute neutrophil count $\left(\times 10^{\wedge} 9 / \mathrm{L}\right), \quad E B M$ expressed breast milk, Na sodium $(\mathrm{mmol} / \mathrm{L})$, K potassium $(\mathrm{mmol} / \mathrm{L}), \quad H C O 3$ bicarbonate $(\mathrm{mmol} / \mathrm{L})$, Urea urea

of vertical transmission are 2\% [2], however, these data are prior to the emergence of the delta variant. In our case, the mother gave birth on day 8 of illness, likely after her period of peak infectiousness. Evidence suggests that viral load peaks within the first 2 days after symptom onset [3]. This likely occurs even earlier with the Delta variant [4]. Due to this, we hypothesise this case represents an example of in-utero transmission. Pathophysiological plausibility and multiple case reports of probable in-utero transmission have been recently well summarised [5]. The cell-membrane associated angiotensin-converting enzyme 2 (ACE-2) receptor and transmembrane protease serine 2 (TMPRSS2) required for SARS-CoV-2 cellular entry have been identified in placental cells [6]. Vascular damage to the placenta could also allow SARS-CoV-2 to reach the fetus without placental cell infection via amniotic fluid.

The low cycle threshold $(\mathrm{Ct}=14)$ of our case's sample on day 3 of life and isolation in viral culture suggests a high viral load and recent infection rather than transient contamination. Neonatal infection was confirmed with persistence of SARS-CoV-2 isolated in viral culture from a nasopharyngeal sample on day 9 of life. Viral culture was performed in a certified PC 3 certified laboratory in Sydney, Australia using the methods described in Stelzer-Braid et al. [7]. A modified cell line, HEK-293 T cells transduced with ACE2 and TMPRSS receptors, was maintained in Dulbecco's Modified Eagle Medium (DMEM) (Life Technologies) supplemented with $10 \%$ FBS and $1 \times$ PSG. On the day of virus culture, cell suspension was prepared in DMEM (Life Technologies) supplemented with $2 \%$ FBS and $1 \times$ PSG. $10^{4}$ cells from cell suspension were dispensed into each well of a 96-well flat-bottom tissue culture plate. HEK-293 T cells $(\mathrm{mmol} / \mathrm{L})$, Creat creatinine $(\mu \mathrm{mol} / \mathrm{L})$, Bilirubin bilirubin $(\mu \mathrm{mol} / \mathrm{L})$, $C P A P$ continuous positive airway pressure, $P C R$ polymerase chain reaction, $H F N P$ high flow nasal prongs, $S V R A$ spontaneous ventilation in room air), $22 \mathrm{kcal}=$ human milk fortifier, 22 kilocalories per ounce of expressed breast milk (EBM)

were then inoculated with $50 \mu \mathrm{L}$ clinical sample (filtered through $0.22 \mu \mathrm{m}$ filter at $10,000 \mathrm{~g}$ for $5 \mathrm{~min}$ ) and incubated at $37{ }^{\circ} \mathrm{C}$ with $5 \% \mathrm{CO}_{2}$. Signs of cytopathogenic effect (CPE) were monitored at day 1 and day 4 post-infection. CPE was observed from day 1 of culture on the nasopharyngeal sample taken from our case on day 3 of life. Whole genome sequencing (Oxford Nanopore Technologies) of the day 3 clinical sample confirmed that the case was infected with the Delta variant (pangolin lenage:AY.39.1; Scorpio call: Delta- B1.617.2-like).

Postnatal transmission is the most commonly described mode of transmission in the literature [2]. We deem this unlikely in our case, as the mother and child were separated immediately after birth and did not have any close contact until after the mother was de-isolated on day 14 of COVID19 illness. The father was not present at the delivery and did not have any contact with the baby until day 5 of life. The baby received EBM prior to testing positive for SARSCoV-2 on day 3 of life, however, replication-competent virus in breast milk has not been described in the literature [8]. Hospital acquired infection inside our Newborn Care Centre is unlikely, because all staff members involved in the care of the baby were tested negative to SARS-CoV-2 as part of our surveillance testing program, and all were fully vaccinated. Intrapartum transmission is also less likely in the context of a pre-labour caesarean section in our case.

Ultimately, we cannot prove or disprove in-utero foetal exposure as we did not perform any testing in-utero or before $24 \mathrm{~h}$ of age. Unlike in the case described by Kulkarni et al. [1] we did not test placental or cord blood samples which would strengthen the case for in-utero transmission. Placental abruption makes peri-partum infection possible. 
However, due to the timing of peak infectiousness of the Delta variant and the isolation of the case from the parents at delivery, we feel in-utero infection is the most likely mode of transmission in our case. Despite previously reported low rates vertical transmission of SARS-CoV-2 in the literature and in-particular scepticism about the potential for in-utero transmission, we believe that these recent symptomatic neonatal cases in the context of the Delta variant warrant further research.

Acknowledgements The authors have no relevant financial or nonfinancial interests to disclose. Written consent from the parents was obtained after discussion with the South East Sydney Local Health District (SESLHD) Human Research Ethics Committee (HREC) on 7th September 2021; 2021/PIDO2664.

\section{Declarations}

Conflict of interest No conflicts of interest.

Open Access This article is licensed under a Creative Commons Attribution 4.0 International License, which permits use, sharing, adaptation, distribution and reproduction in any medium or format, as long as you give appropriate credit to the original author(s) and the source, provide a link to the Creative Commons licence, and indicate if changes were made. The images or other third party material in this article are included in the article's Creative Commons licence, unless indicated otherwise in a credit line to the material. If material is not included in the article's Creative Commons licence and your intended use is not permitted by statutory regulation or exceeds the permitted use, you will need to obtain permission directly from the copyright holder. To view a copy of this licence, visit http://creativecommons.org/licenses/by/4.0/.

\section{References}

1. Kulkarni R, Rajput U, Dawre R, et al. Early-onset symptomatic neonatal COVID-19 infection with high probability of vertical transmission. Infection. 2021;49:339-43. https://doi.org/10.1007/ S15010-020-01493-6.

2. Raschetti R, Vivanti AJ, Vauloup-Fellous C, Loi B, Benachi A, De Luca D. Synthesis and systematic review of reported neonatal SARS-CoV-2 infections. Nat Commun. 2020;11:1-10. https://doi. org/10.1038/s41467-020-18982-9.

3. Cevik M, Tate M, Lloyd O, Maraolo AE, Schafers J, Ho A. SARSCoV-2, SARS-CoV, and MERS-CoV viral load dynamics, duration of viral shedding, and infectiousness: a systematic review and meta-analysis. Lancet Microbe. 2021;2:e13-22. https://doi.org/10. 1016/S2666-5247(20)30172-5.

4. Li B, Deng A, Li K, et al. Viral infection and transmission in a large well-traced outbreak caused by the delta SARS-CoV-2 variant. medRxiv. 2021. https://doi.org/10.1101/2021.07.07.21260 122.

5. Moore KM, Suthar MS. Comprehensive analysis of COVID-19 during pregnancy. Biochem Biophys Res Commun. 2021;538:180. https://doi.org/10.1016/J.BBRC.2020.12.064.

6. Algarroba G, Rekawek P, Vahanian S, et al. Visualization of severe acute respiratory syndrome coronavirus 2 invading the human placenta using electron microscopy. Am J Obstet Gynecol. 2020;223:275-8. https://doi.org/10.1016/J.AJOG.2020.05.023.

7. Stelzer-Braid S, Walker GJ, Aggarwal A, et al. Virus isolation of severe acute respiratory syndrome coronavirus 2 (SARS-CoV-2) for diagnostic and research purposes. Pathology. 2020;52:760-3. https://doi.org/10.1016/J.PATHOL.2020.09.012.

8. Demers-Mathieu V, Do DM, Mathijssen GB, et al. Difference in levels of SARS-CoV-2 S1 and S2 subunits- and nucleocapsid protein-reactive SIgM/IgM, IgG and SIgA/IgA antibodies in human milk. J Perinatol 2020;41:850-859 https://doi.org/10.1038/ s41372-020-00805-w 